\title{
The Role of Sonic Hedgehog of Neural Origin in Thalamic Differentiation in the Mouse
}

\author{
Nora-Emöke Szabó, Tianyu Zhao, Xunlei Zhou, and Gonzalo Alvarez-Bolado \\ Department of Genes and Behavior, Max Planck Institute of Biophysical Chemistry, D-37077 Göttingen, Germany
}

\begin{abstract}
The specification of the intricate neuronal assemblies that characterize the forebrain is not well understood. The ventral spinal cord is specified through a concentration gradient of Sonic hedgehog (Shh) protein secreted by the notochord. Shh is expressed also in the forebrain neuroepithelium (neural Shh) and the underlying notochord and prechordal plate. Neural Shh is essential for the development of the prethalamus (ventral thalamus), but its effects on the thalamus (dorsal thalamus) are still unclear. We hypothesized that neural Shh would act on a previously regionalized dorsal diencephalic region to promote the emergence of specific thalamic nuclear and histological traits. To find out, we generated a conditional mouse mutant line specifically lacking Shh expression in the diencephalic neuroepithelium. We show that the transcription factor Gbx2, required for thalamic development downstream Shh, is expressed in our mutant in a restricted thalamic region and is necessary and sufficient for the differentiation of the medial and intralaminar thalamic nuclei. In the rest of the thalamus, neural $S h h$ is required to promote neuronal aggregation into nuclei as well as axonal extension. In this way, the individual thalamic nuclei show differential dependence on $S h h, G b x 2$, or both for their differentiation. Additionally, Gbx2 is required for the survival of thalamic neurons.
\end{abstract}

Key words: apoptosis; conditional mutant; Foxb1; Gbx2; Shh; thalamus

\section{Introduction}

Brain regions differentiate stepwise, receiving first general regional specification during gastrulation and progressing down a genetic regulatory hierarchy. This cascade ends in the effector genes that direct formation of neuronal nuclei and confer mature functional attributes to neurons. Transient embryonic structures called organizers and their secreted products are key in this process. The best known model is the specification of ventral spinal cord neurons through Sonic hedgehog (Shh) protein secreted by the notochord (Dessaud et al., 2008). Shh is expressed in the forebrain neuroepithelium (neural $S h h$ ) and the underlying notochord and prechordal plate. If and how the mechanisms found in the ventral spinal cord have become modified to specify the convoluted three-dimensional neuronal assemblies found in the forebrain is not well understood. The thalamus (dorsal thalamus) is a forebrain region constituted mostly by neurons projecting to cortex and striatum, and, in rodents, it can be subdivided into several nuclear groups harboring altogether $>30$ nuclei and subnuclei (Swanson, 1992). These differ from each other specifically in position, morphology, marker expression, membrane properties, and cortical targets (Jones, 2007a). Thalamic subdivisions

\footnotetext{
Received Sept. 22, 2008; revised Jan. 14, 2009; accepted Jan. 22, 2009.

This work was supported by the Max Planck Society. Drs. Gail Martin (University of California, San Francisco) and Alex Joyner (Sloan-Kettering Cancer Center, New York) provided the Gbx2 mutant mouse line. Dr. Ulrike Teichmann and her team took expert care of the mutant colonies.

This article is freely available online through the J Neurosci Open Choice option.

Correspondence should be addressed to Gonzalo Alvarez-Bolado, Department of Genes and Behavior, Max Planck Institute of Biophysical Chemistry, Am Fassberg 11, D-37077 Göttingen, Germany. E-mail: gonzalo.alvarez-bolado@mpibpc.mpg.de.

DOI:10.1523/JNEUROSCI.4524-08.2009

Copyright $\odot 2009$ Society for Neuroscience $\quad$ 0270-6474/09/292453-14\$15.00/0
}

originate as five undifferentiated cell masses or pronuclei that gradually resolve into specific nuclear groups: central pronucleus (anterior, ventral, and intralaminar groups), dorsal pronucleus (lateral and posterior groups), medial pronucleus (medial group), lateral geniculate pronucleus, and medial geniculate pronucleus (Rose, 1942; Jones, 2007b).

Neural Shh [from the zona limitans interthalamica (ZLI) and diencephalic tegmentum] is essential for prethalamus (ventral thalamus) specification (Kiecker and Lumsden, 2004; Vieira et al., 2005; Zeltser, 2005; Scholpp et al., 2006; Vieira and Martinez, 2006), but its role in (dorsal) thalamic development is still unclear. Shh controls thalamic expression of transcription factor gene Gbx2 (Hashimoto-Torii et al., 2003), required for thalamic development (Miyashita-Lin et al., 1999; Hevner et al., 2002). We hypothesized that the role of neural Shh would be to take over the last steps of the thalamic specification cascade, which lead to the emergence of specific thalamic histogenesis and nucleogenesis, and that this would be done in part through activation of $G b \times 2$.

To address this question, we analyzed thalamic differentiation in the Gbx2 mutant and in a conditional mutant lacking diencephalic Shh expression. We found that, in the neural Shh-deficient diencephalon, Gbx2 is expressed by default in a restricted area and is necessary and sufficient for the development of the medial and intralaminar thalamic nuclei. The rest of the thalamus requires neural Shh to promote proper migration and neuronal aggregation into nuclei as well as axonal extension. Therefore, the individual thalamic nuclei form three groups according to their dependence on neural Shh, Gbx2, or both for their differentiation. Additionally, we show that Gbx2 is essential for neuronal survival in the prenatal thalamus. 


\section{Materials and Methods}

Mouse lines

Experiments with animals were performed in accordance with the European Communities Council Directive of November 24, 1986 (86/609/EEC) and under authorization of Az 32.22/Vo (“Ordnungsamt der Stadt Göttingen”). To obtain embryos and fetuses for the analysis, timed-pregnant females of the appropriate crossings were killed by cervical dislocation.

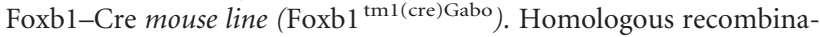
tion was used to replace the Foxb1 coding sequence by the Cre recombinase cDNA, and a mouse line was created (kept in the C57BL/6 background) (Zhao et al., 2007). This line expresses Cre under the control of the regulatory sequences of Foxb1. All mutant mice used for our study were heterozygous for Foxb1 $1^{\mathrm{Cre}}$, and therefore they were heterozygous for Foxb1 and showed normal phenotype as expected (Alvarez-Bolado et al., 2000; Kloetzli et al., 2001). No homozygotes were used in this study.

Floxed Shh mouse line (Shh ${ }^{\mathrm{tm} 2 \mathrm{Amc}}$ ). This line was generated by Dr. MacMahon (Harvard University, Cambridge, MA) (Dassule et al., 2000) and obtained through The Jackson Laboratory. In these mice, exon 2 of the Shh locus [which encodes approximately half of the active N-terminal Shh signal that is essential for Shh function (Fan et al., 1995; Hynes et al., 1995; López-Martínez et al., 1995; Martí et al., 1995; Roelink et al., 1995)] is flanked with loxP sites. The same floxed line has been used for the study of the developing limb (Lewis et al., 2001).

Foxb ${ }^{\text {tm1(cre)Gabo }} \times$ Shh $^{\text {tm2Amc }}$ (Shh-c). After crossing the floxed Shh line with a Cre line, a mutant mouse line is generated $(S h h-c)$ carrying a recombined (i.e., inactive) Shh locus in Cre-expressing cells. Because the caudal diencephalon (including the thalamus) belongs entirely to the Foxb1 lineage, i.e., expresses Cre in the Foxb1-Cre line (Zhao et al., 2008), this line lacks functional Shh in the diencephalic neuroepithelium (see Results). When Shh expression is activated, the recombined Shh locus produces a truncated mRNA lacking exon 2. In situ hybridization (ISH) probes can be designed against the $3^{\prime}$ untranslated region (UTR), labeling all Shh mRNA forms, either full length (functional) or truncated (nonfunctional). Probes against exon 2, however, label only the full-length form.

Gbx2 mutant mouse line. In this line, provided by Drs. Gail Martin and Alex Joyner, all coding sequences of exon 2, including the homeobox, have been deleted (Wassarman et al., 1997). A portion of the 3' UTR of $G b \times 2$ remains unaltered in the targeted $G b \times 2$ locus (Wassarman et al., 1997), and in situ hybridization probes against this sequence can label the expression of Gbx2 mRNA (although lacking the homeodomain and therefore nonfunctional) in the $G b \times 2$ mutant (see Results).

Reporter lines. To map the embryonic brain region in which Cremediated recombination takes place, we crossed our mice with the ROSA26R reporter mouse line (Soriano, 1999). In ROSA26R animals, the reporter gene $\beta$-galactosidase is inserted in the constitutively active ROSA locus downstream a floxed stop codon. During Cre-mediated recombination, the stop codon is deleted and $\beta$-galactosidase is constitutively produced. This reporter is a lineage marker because, in mice carrying both the Foxb $1^{\text {Cre }}$ and the ROSA26R alleles, cells expressing Foxb1 and any cell derived from them will permanently express $\beta$-galactosidase. To label the axons of neurons of the Foxb1 lineage, we crossed our Foxb1 ${ }^{\text {Cre }}$ mice with the Z/AP (Lobe et al., 1999) reporter mouse line (C57BL/6) (see below, Axonal labeling by alkaline phosphatase activity). In Z/AP animals, Cre-mediated recombination activates constitutive expression of human placental alkaline phosphatase (hPLAP). This reporter is also a lineage marker.

\section{Axonal labeling by alkaline phosphatase activity}

In Foxb1 ${ }^{\text {Cre }}$ Z/AP animals, Foxb1 lineage neurons will express hPLAP. Because hPLAP attaches to axonal membranes, it is a marker of axons of lineage-labeled neurons (Fields-Berry et al., 1992; Gustincich et al., 1997; Leighton et al., 2001).

Alkaline phosphatase activity detection. This protocol has been described previously (Lobe et al., 1999). Briefly, brains of the appropriate genotypes were collected, fixed (4\% paraformaldehyde) on ice for 60 min, agarose embedded, cut into $150-\mu \mathrm{m}$-thick sections, fixed again $(4 \%$ paraformaldehyde $/ 0.2 \%$ glutaraldehyde) on ice for $60 \mathrm{~min}$, incubated for $30 \mathrm{~min}$ at $72^{\circ} \mathrm{C}$ to inhibit endogenous phosphatase, rinsed in alkaline phosphatase buffer (in mm: 100 Tris- $\mathrm{Cl}, \mathrm{pH} 9.5,100 \mathrm{NaCl}$, and 10
$\mathrm{MgCl}_{2}$ ), incubated with staining solution (250 $\mu$ l of nitrobluetetrazolium-chloride plus $187.5 \mu \mathrm{l}$ of 5-bromo-4-chlor-indolylphosphate per $50 \mathrm{ml}$ of alkaline phosphatase buffer) overnight $\left(4^{\circ} \mathrm{C}\right)$, and fixed (4\% paraformaldehyde) for $60 \min \left(4^{\circ} \mathrm{C}\right)$.

\section{In situ hybridization in whole mount}

ISH was performed as described previously (Wilkinson, 1992). The probes were cloned by PCR (primers available on request). Briefly, the embryos were fixed in paraformaldehyde $4 \%$ in PBS overnight $\left(4^{\circ} \mathrm{C}\right)$, washed in PBS plus $0.1 \%$ Tween 20 (PBT), and stored at $-20^{\circ} \mathrm{C}$ in methanol. For ISH, the embryos were rehydrated, bleached $\left(6 \% \mathrm{H}_{2} \mathrm{O}_{2}\right)$, digested $[10 \mu \mathrm{g} / \mathrm{ml}$ proteinase $\mathrm{K}$ in PBT at room temperature (RT)], washed ( $2 \mathrm{mg} / \mathrm{ml}$ glycine/PBT), postfixed (4\% paraformaldehyde $/ 0.2 \%$ glutaraldehyde/PBT), prehybridized for $1-2 \mathrm{~h}\left(70^{\circ} \mathrm{C}\right)$, and hybridized overnight $\left(70^{\circ} \mathrm{C}\right)$. They were then washed $(50 \%$ formamide, $5 \times \mathrm{SSC}, \mathrm{pH}$ 4.5 , and $1 \%$ SDS at $70^{\circ} \mathrm{C}$ ), rinsed $[100 \mathrm{~mm}$ maleic acid, $150 \mathrm{~mm} \mathrm{NaCl}, 2$ mu levamisole, and $0.1 \%$ Tween 20 (MAB)], and incubated in $10 \%$ sheep serum in $\mathrm{MAB} / 2 \%$ blocking reagent (Roche Diagnostics) for $2-3 \mathrm{~h}$ (RT) and then in anti-digoxigenin alkaline phosphatase antibody (Roche Diagnostics) overnight $\left(4^{\circ} \mathrm{C}\right)$. The embryos were rinsed and then left in MAB overnight $\left(4^{\circ} \mathrm{C}\right)$. The embryos were then incubated in BM-Purple (Roche Diagnostics) with levamisole (RT) and, after color developed, washed in PBT, pH 4.5, fixed in $4 \%$ formaldehyde $/ 0.1 \%$ glutaraldehyde overnight $\left(4^{\circ} \mathrm{C}\right)$, and transferred into $80 \%$ glycerol/PBT.

\section{ISH on sections}

Nonradioactive ISH was performed on cryosections ( $15 \mu \mathrm{m}$ thick) that were fixed in $4 \%$ paraformaldehyde and acetylated after sectioning. Prehybridization, hybridization, and washing steps were performed with the help of an automatic liquid-handling unit (Genesis RSP 200; Tecan), and the digoxigenin-labeled probe was detected by a dual-amplification procedure (Yaylaoglu et al., 2005; Visel et al., 2006).

\section{Bromodeoxyuridine labeling}

Pregnant mice from appropriate crossings were intraperitoneally injected with bromodeoxyuridine (BrdU) (RPN201; GE Healthcare) (50 $\mu \mathrm{g} / \mathrm{g}$ body weight). For short survival data, we injected at approximately embryonic day 12.75 (E12.75) (at 6:00 P.M. on day 12 postcoitum) and collected the embryos either 1.5 or $3 \mathrm{~h}$ later. According to thalamic birthdating data (Altman and Bayer, 1988; Clancy et al., 2001, 2007), at this stage, neurons are being produced in all areas of the thalamic neuroepithelium. For long-term survival, we injected BrdU on day E12.5 at 12:00 P.M., 3:00 P.M., and 6:00 P.M. (Takahashi et al., 1993) and collected the fetuses at E18.5.

We detected cell proliferation on cryosections $(10 \mu \mathrm{m})$ by means of anti-BrdU antibody M0744 (1:100) (Dako), after epitope retrieval in $2 \mathrm{M}$ $\mathrm{HCl}$ for $30 \mathrm{~min}$ at $37^{\circ} \mathrm{C}$. We used the nuclear marker $4^{\prime}, 6$-diamidino-2phenylindole dihydrochloride (DAPI) (Invitrogen) as a counterstain. In the short-survival animals (E12.75), we examined the sections under confocal microscopy and counted BrdU-labeled and unlabeled cells in $100-\mu \mathrm{m}$-wide bins encompassing the width of the neuroepithelium (apical to basal side) at three rostrocaudal levels and calculated the labeling index (BrdU-labeled cells as percentage of total cells) (Takahashi et al., 1993; Warren et al., 1999; Ishibashi and McMahon, 2002).

\section{Apoptosis detection}

We selected cryostat sections of E12.5 and E18.5 brains at three thalamic rostrocaudal levels in three individuals per genotype (wild type, Shh-c, $\left.G b \times 2^{-/-}\right)$. We pretreated the sections with $4 \%$ paraformaldehyde $(20$ $\mathrm{min})$ and proteinase $\mathrm{K}(1.5 \mu \mathrm{g} / \mathrm{ml}, 5 \mathrm{~min})$ at room temperature and then labeled the apoptotic cells with the ApopTag TUNEL (terminal deoxynucleotidyl transferase-mediated biotinylated UTP nick end labeling) kit (Millipore Bioscience Research Reagents) according to the instructions of the manufacturer. We used DAPI as counterstain and counted absolute number of apoptotic cells per histological section of the thalamus (both sides) under high magnification in three individuals per genotype.

\section{Statistical analysis}

ANOVA of the cell counting results (BrdU and apoptosis) was performed with Prism software (GraphPad Software). 


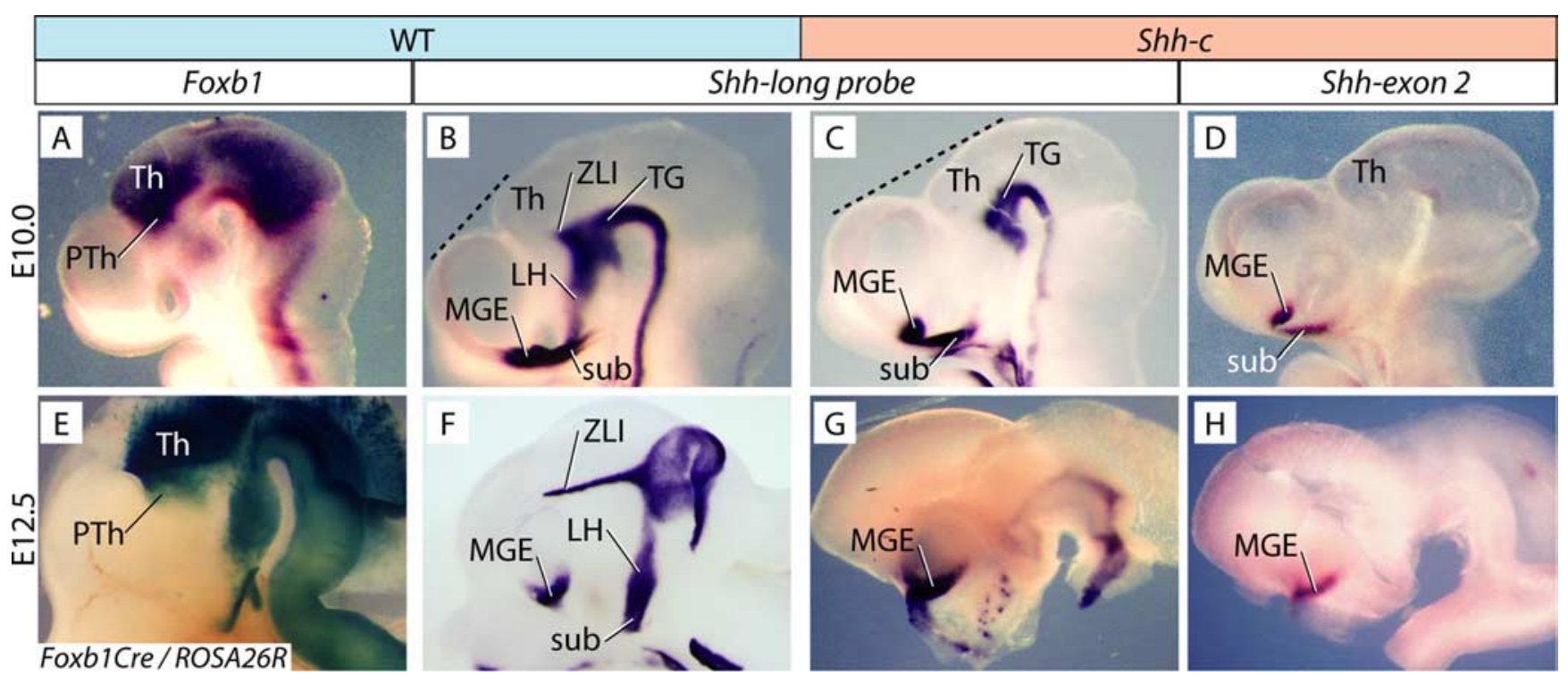

Figure 1. Abolition of functional Shh expression in the Shh-c caudal diencephalon. $\boldsymbol{A}-\boldsymbol{D}, \boldsymbol{F}-\boldsymbol{H}$, Whole-mount in situ hybridization for the genes and genotypes indicated. $\boldsymbol{E}$, Foxb 1 lineage mapping by $\beta$-galactosidase detection in Foxb1 ${ }^{\text {Cre }} /$ ROSA26R heterozygotes. $A, B, A t E 10.0$, Foxb1 expression ( $\boldsymbol{A}$ ) overlaps with the incipient ZLl as labeled by Shh (B). $\boldsymbol{C}, \boldsymbol{D}$, In the Shh-cmutant, Shh transcription is not active in the ZLI but in the diencephalic tegmentum (C). An exon 2 probe shows that all diencephalic Shh mRNA at this age is nonfunctional (D). The dotted lines in $\boldsymbol{B}$ and $\boldsymbol{C}$ show that the mutant thalamus is smaller. $\boldsymbol{E}, \boldsymbol{F}$, At E12.5, Foxb 1 lineage labeling is present in most of the thalamic region (E), overlapping thalamus and ZLI as labeled by Shh $(\boldsymbol{F})$. The Shh-c mutant shows almost no Shh transcriptional activation in the caudal diencephalon $(\boldsymbol{G})$ and no functional Shh at all $(\boldsymbol{H})$. For the abbreviations used in the figures, see Table 1.

Table 1. Abbreviations used for thalamic and other structures

\begin{tabular}{|c|c|c|}
\hline Pronucleus & Abbreviation & Name \\
\hline \multirow[t]{5}{*}{ Central } & ATN & Anterior thalamic nuclei \\
\hline & VEN & Ventral group \\
\hline & VM & Ventromedial \\
\hline & VMb & Ventromedial basal \\
\hline & VP & Ventral posterior \\
\hline \multirow[t]{6}{*}{ Medial } & PV & Paraventricular \\
\hline & PT & Paratenial \\
\hline & MV & Medioventral \\
\hline & MD & Mediodorsal \\
\hline & $\mathrm{CM}$ & Centromedial \\
\hline & $\mathrm{CL}$ & Centrolateral \\
\hline \multirow[t]{3}{*}{ Dorsal } & LD & Laterodorsal \\
\hline & $\mathrm{LP}$ & Lateral posterior \\
\hline & Po & Posterior \\
\hline Lateral geniculate & LGd & Lateral geniculate dorsal \\
\hline Medial geniculate & MG & Medial geniculate \\
\hline \multirow[t]{16}{*}{ Other structures } & Ctx & Cortex \\
\hline & $\mathrm{DG}$ & Dentate gyrus (hippocampus) \\
\hline & $\mathrm{Em}$ & External medullary lamina \\
\hline & $\mathrm{H}$ & Habenula (epithalamus) \\
\hline & Ic & Internal capsule \\
\hline & $\mathrm{LH}$ & Lateral hypothalamus band \\
\hline & $M B$ & Midbrain \\
\hline & MGE & Medial ganglionic eminence \\
\hline & PTh & Prethalamus (ventral thalamus) \\
\hline & Rf & Retroflex fascicle \\
\hline & RT & Reticular nucleus \\
\hline & sub & Suboptical Shh domain \\
\hline & Te & Thalamic eminence \\
\hline & TG & Diencephalic tegmentum \\
\hline & Th & Thalamus (dorsal thalamus) \\
\hline & ZLI & Zona limitans interthalamica \\
\hline
\end{tabular}

\section{Results}

Abolition of functional Shh expression and of Shh signaling in the caudal diencephalon of $S h h-c$ mutants

At E10.0, Foxb1 is expressed in the prethalamus and thalamus
Table 2. Pronuclear markers in the wild-type thalamus

\begin{tabular}{|c|c|c|c|c|c|c|}
\hline Pronuclei & Nuclei & Calb2 & $G b \times 2$ & $2 h \times 2$ & Neurog2 & Cdh6 \\
\hline \multirow[t]{4}{*}{ Central } & ATN & & & & + & + \\
\hline & VP & & & & + & + \\
\hline & VM & & & + & + & + \\
\hline & VMb & + & + & + & & + \\
\hline \multirow[t]{4}{*}{ Medial } & PV, PT, MV & + & + & + & & \\
\hline & MD & & + & & & \\
\hline & $C M$ & + & + & + & & + \\
\hline & $\mathrm{CL}$ & + & + & + & & \\
\hline \multirow[t]{3}{*}{ Dorsal } & LD & + & & + & + & \\
\hline & $\mathrm{LP}$ & + & + & + & & + \\
\hline & Po & & & & & + \\
\hline Lateral geniculate & LGd & & & & + & + \\
\hline Medial geniculate & MG & + & + & + & & + \\
\hline
\end{tabular}

+ indicates expression in a recognizable structure (listed in the left column). Intensity of expression has not been recorded.

(Fig. 1A), overlapping the domain of the incipient ZLI (Fig. 1B) (Zhao et al., 2008). In Shh-c mutants at this age, Shh expression has been abolished in the ZLI as well as in domains of the rostral diencephalon (Fig. 1C). As expected (Ishibashi and McMahon, 2002), the caudal diencephalon is smaller in the mutant (Fig. $1 B, C$, dotted line). An in situ probe specifically labeling fulllength Shh mRNA (Shh-exon 2 probe; see Materials and Methods) failed to label the mutant diencephalon (Fig. $1 D$ ), demonstrating that the Shh-c neuroepithelium does not produce functional Shh mRNA. The telencephalic Shh expression domains were intact (Fig. 1D, MGE and sub), because they do not overlap with Foxb1 expression (Fig. 1A). At E12.5, all major regions of the brain can be recognized by specific marker expression (Shimamura et al., 1995). At this age, Foxb1 drives Cre recombination activity in the caudal diencephalon, dorsal and ventral (as reflected by lineage labeling in ROSA26R crossings; Fig. $1 E$ ) (Zhao et al., 2008). In wild-type embryos, Shh showed a very pronounced and characteristic expression pattern in the caudal diencephalon (Fig. 1F, ZLI and TG) as well as the rostral diencephalon (hypothalamus) (Fig. $1 F$, LH). In the Shh-c mu- 


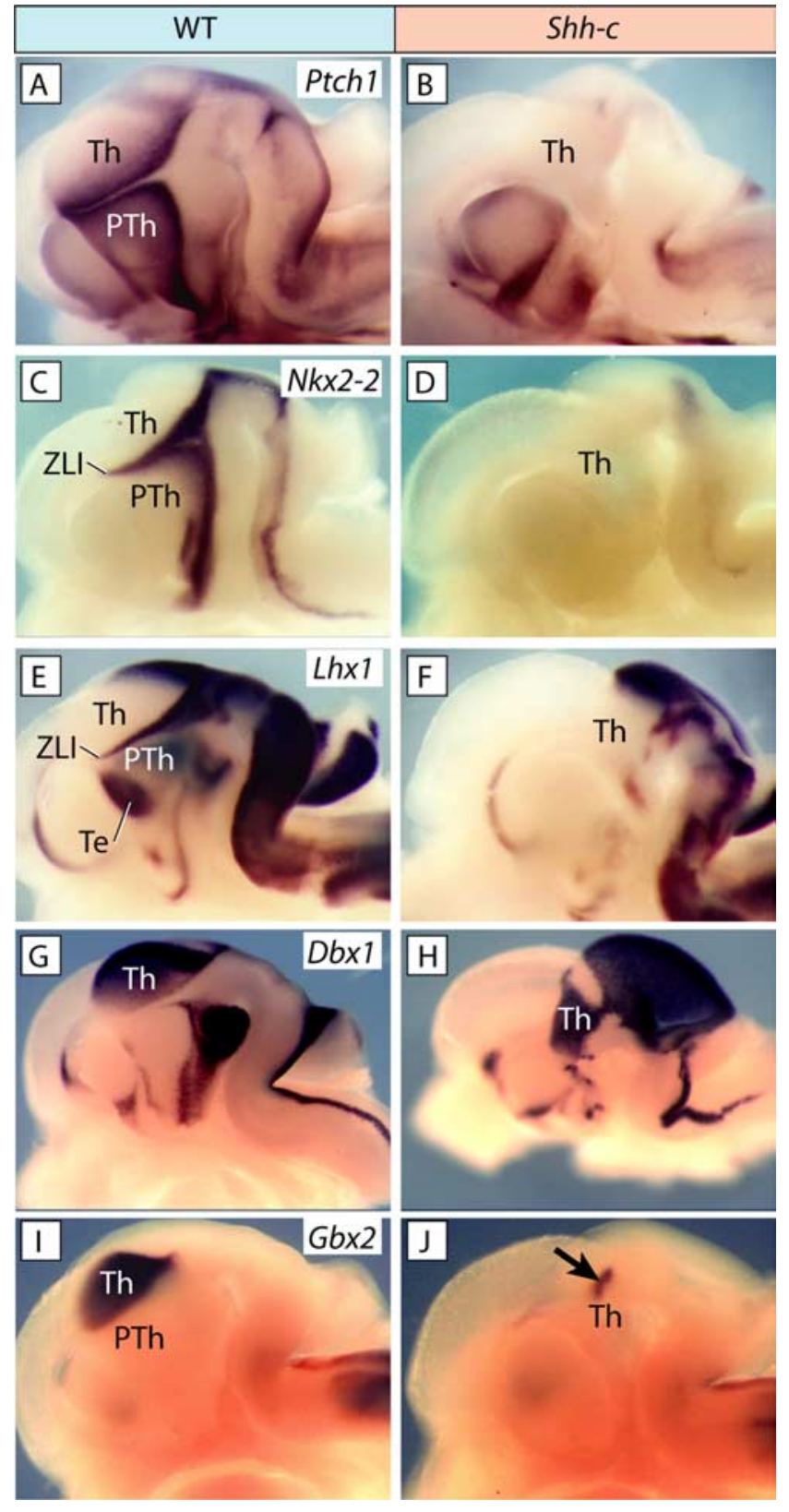

Figure 2. Thalamic regionalization in Shh-c mutants. Whole-mount in situ hybridization of hemisected E12.5 mouse brains, probes, and genotypes as indicated. $A, B$, Lack of Ptch 1 expression indicates that the Shh signaling pathway is abolished in the Shh-c mutant diencephalon. $\boldsymbol{C}-\boldsymbol{F}$, The ZLI has disappeared in the Shh-c mutant, as determined by expression of $N k \times 2-2$ and Lhx1. $\boldsymbol{G}, \boldsymbol{H}$, Thalamic expression of $D b \times 1$ is preserved in the mutant. $I, J, G b x 2$ is expressed in a small restricted thalamic domain at E12.5 in the Shh-c mutant (arrow in $J$ ).

tant, expression of Shh was absent from the diencephalon (Fig. $1 G$ ), and this was confirmed by an exon 2 probe (Fig. $1 H$ ). Expression of Shh receptor Ptch1 is diagnostic of a functioning Shh signaling pathway (for review, see Lewis et al., 2001). Ptch1 labeled the wild-type thalamus at this age (Fig. $2 A$ ) but was absent in the Shh-c mutant caudal diencephalon (Fig. 2B), indicating Shh pathway abolition in this region.

\section{Abolition of the ZLI in the Shh-c mutant mouse}

Other ZLI markers confirmed lack of this domain in the mutant. Expression of ZLI marker gene Nkx2-2, which is downstream Shh (Kitamura et al., 1997; Kiecker and Lumsden, 2004), was absent from the Shh-c mutant (Fig. 2C,D). Expres-
Table 3. Markers and nuclei in the Shh-c thalamus

\begin{tabular}{llccccc}
\hline Pronuclei & Nuclei & Calb2 & Gbx2 & Lhx2 & Neurog2 & Cdh6 \\
\hline Central & ATN & & & & - & $?$ \\
& VP & & & & $?$ & $?$ \\
& VM & & & $?$ & $?$ & $?$ \\
Medial & VMb & $?$ & + & $?$ & & $?$ \\
& PV, PT, MV & + & + & + & & \\
& MD & & + & & & \\
Dorsal & CM & & + & + & & $?$ \\
& CL & & + & + & & $?$ \\
Lateral geniculate & LGd & & & - & - & $?$ \\
Medial geniculate & MG & + & + & - & & $?$ \\
\hline
\end{tabular}

? indicates "normal" marker expression in a morphologically altered part of the thalamus identified by its position along the anteroposterior and dorsoventral axes and comparison with wild type. - indicates abnormal lack of expression. + indicates normal expression in a readily recognizable structure.

sion of transcription factor gene $L h x 1$, a marker of the zona limitans, prethalamus, and thalamic eminence (Bachy et al., 2001), was also absent from the Shh-c ZLI (Fig. 2E,F). To evaluate the thalamus of the $S h h-c$ mutant, we used expression of specific markers Dbx1 (Shoji et al., 1996; Ishibashi and McMahon, 2002) and Gbx2 (Miyashita-Lin et al., 1999; Hevner et al., 2002). In the Shh-c thalamus, Dbxl was still expressed (Fig. $2 G, H$ ), indicating that initial regional specification of the thalamus has taken place in the mutant. $G b \times 2$ was reduced to a very small domain (Fig. $2 I, J$ ).

\section{Specific markers in the wild-type thalamus}

To explore thalamic differentiation, we chose five marker genes whose thalamic expression has been established: Calb2-Calretinin (Arai et al., 1991, 1994; Winsky et al., 1992; Frassoni et al., 1998), Gbx2 (Jones and Rubenstein, 2004), Lhx2 (Nakagawa and O'Leary, 2001), Neurog2 (Nakagawa and O'Leary, 2001), and Cdh6 (Jones and Rubenstein, 2004). Because the Shh-c mutants survive up to E18.5, we performed our analysis of the wild type also at this age. We first determined marker expression on transverse sections of E18.5 wild-type thalamus, at four rostrocaudal thalamic levels (Fig. 3, Tables 1, 2).

Central pronucleus (anterior and ventral nuclear groups)

The anterior group was labeled by Lhx2 (weakly), Neurog2, and Cdh6 (Fig. 3C-E,H-J, ATN). The ventral group was labeled by Lhx2, Neurog2, and Cdh6 (Fig. 3M-O, VP and VM). The "tail" of the central pronucleus, represented by the ventromedial basal, was labeled by Calb2, Gbx2, $L h \times 2$, and $C d h 6$ (Fig. $3 P-R, T, \mathrm{VMb}$ ).

Medial pronucleus (medial and intralaminar nuclear groups) We include the intralaminar nuclei in the medial pronucleus (not in the central, as did Rose, 1942) because of marker and phenotype similarity (see below and Discussion). All derivatives of this pronucleus expressed $G b x 2$ (Fig. $3 B, G, \mathrm{~L}, \mathrm{CL}, \mathrm{CM}, \mathrm{MD}, \mathrm{MV}, \mathrm{PT}$, PV). Additionally, they (except the mediodorsal nucleus) expressed Calb2 and Lhx2 (Fig. $3 A-C, F-H, K-M$ ).

Dorsal pronucleus (lateral and posterior nuclear groups)

The laterodorsal nucleus expressed Calb2, Lhx2, and Neurog2 (Fig. $3 F, H, I$, LD). The lateral posterior nucleus was labeled by Calb2, Gbx2, and Cdh6 (Fig. $3 \mathrm{~K}, L, O$, LP). The posterior nucleus expressed Cdh6 (Fig. 3O, Po). 


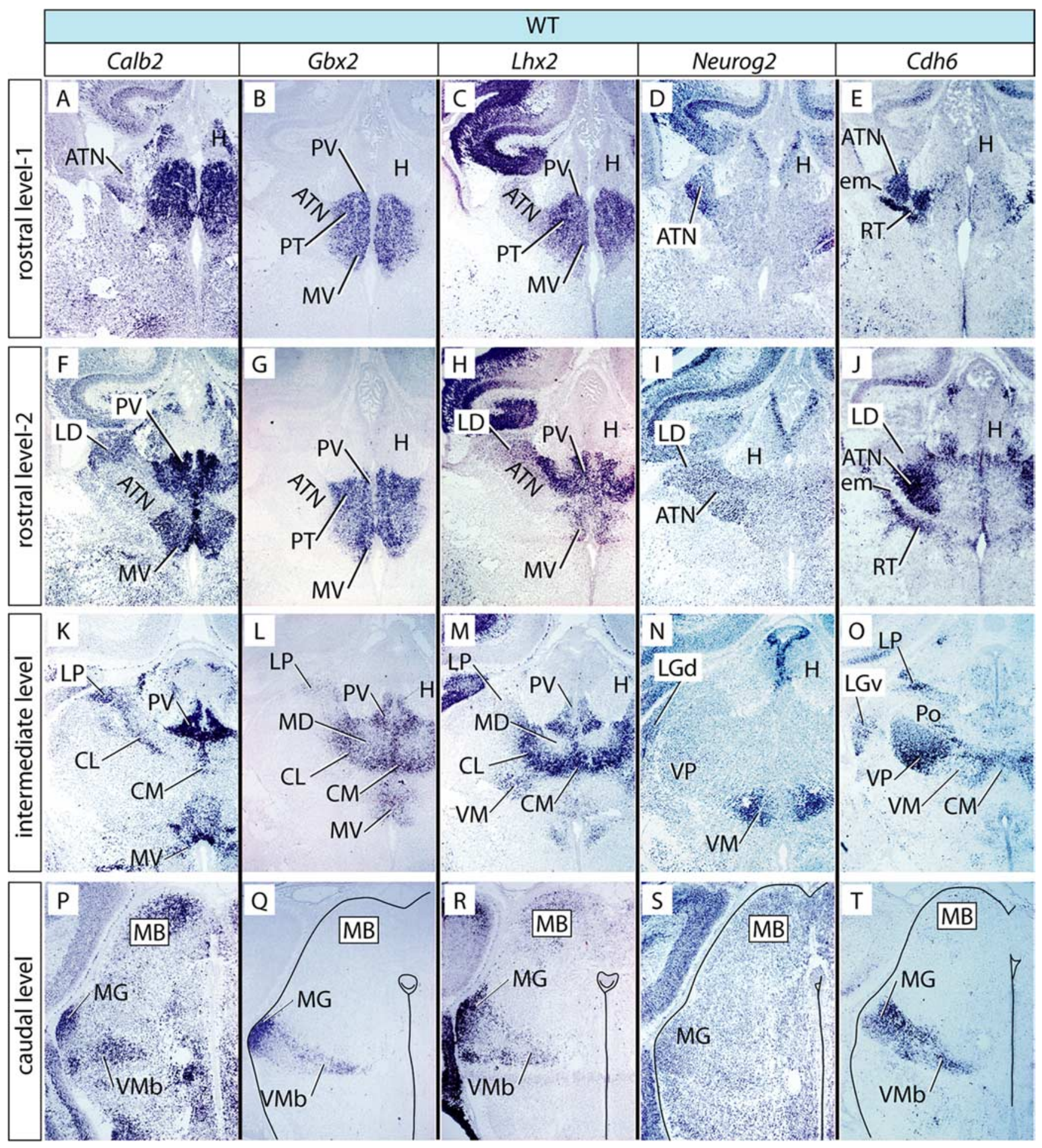

Figure 3. Marker expression in the E18.5 wild-type thalamus. A-I, In situ hybridization on E18.5 mouse brain sections for five marker genes as indicated on top of each column. Rows show sections at given rostrocaudal levels, as indicated on the left side, labeled for each of the five markers. Columns correspond to four rostrocaudal levels labeled with the same probe. Some structures have been outlined for clarity. For details, see Results.

Lateral geniculate pronucleus

The lateral geniculate pronucleus was labeled by Neurog2 and Cdh6 (Fig. $3 \mathrm{~N}, \mathrm{O}, \mathrm{LG}$ ).

\section{Medial geniculate pronucleus}

The medial geniculate pronucleus was labeled by Calb2, Gbx2, Lhx2, and Cdh6 (Fig. 3P-R,T, MG).
General appearance of the $S h h-c$ thalamus

In the Shh-c brain, the prethalamus is absent so that the thalamus "hangs" over the third ventricle, particularly on rostral sections (Fig. 4A-J). At caudal levels, the Shh-c thalamus was embedded into the midbrain (Fig. $4 K-T$ ). By counting the number of histological sections, we estimated that the Shh-c thalamus was smaller than the wild type, on the rostrocaudal 


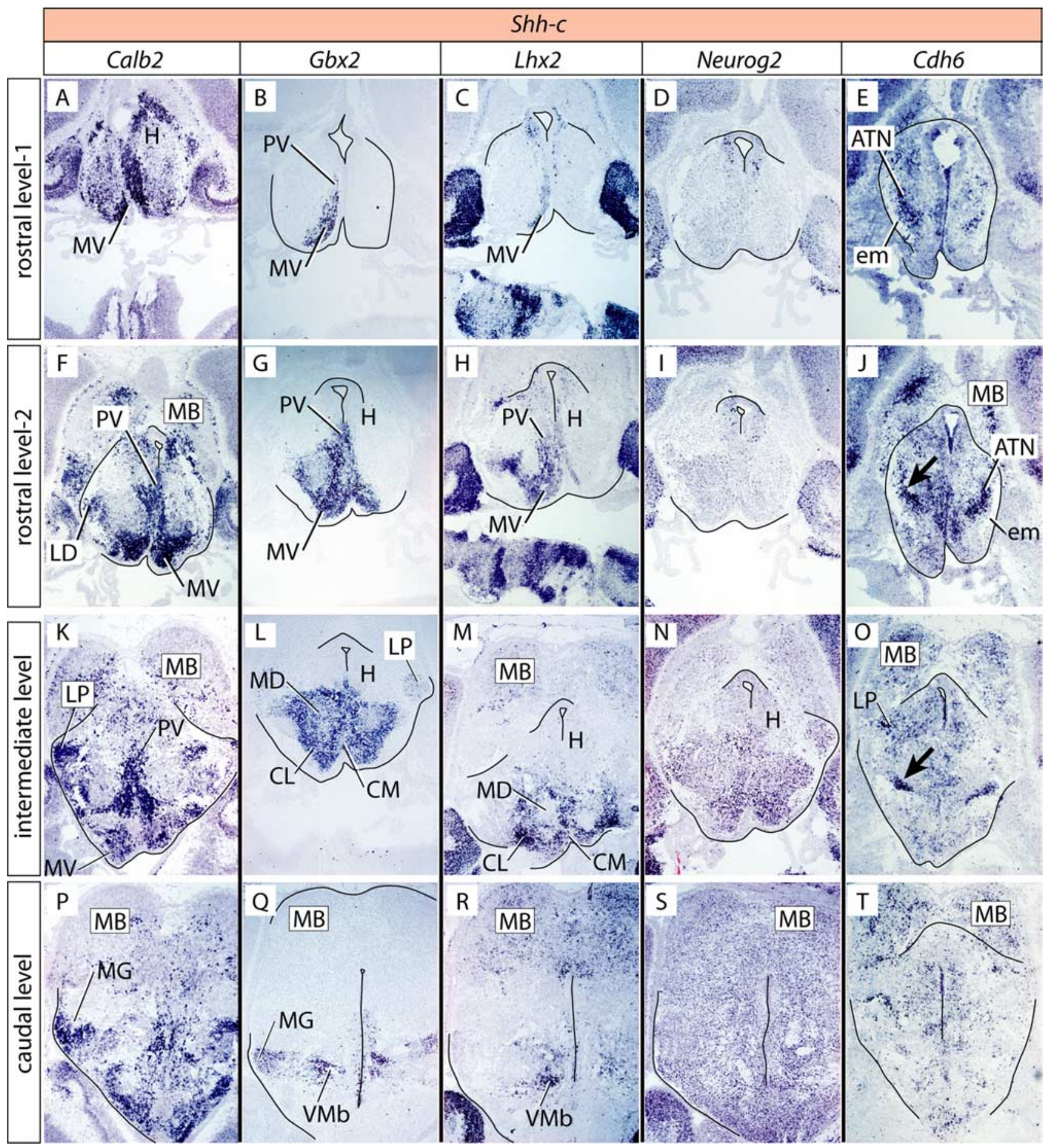

Figure 4. Marker expression in the E18.5 Shh-c thalamus. A-T, In situ hybridization on E18.5 mouse brain sections for five marker genes as indicated on top of each column. Rows show sections at a given rostrocaudal level, as indicated on the left side, labeled for each of the five markers. Columns correspond to four rostrocaudal levels labeled with the same probe. The arrows in $J$ and $\mathbf{O}$ mark continuous rostrocaudal expression of $C d h 6$ in the central pronucleus. Some structures have been outlined for clarity. For details, see Results.

axis, by $\sim 50 \%$, as could be expected (Ishibashi and McMahon, 2002).

Despite gross morphological alteration, the general position of the nuclear groups in the rostrocaudal and dorsoventral axes was correct. Comparison of Tables 2 and 3 shows that, in the Shh-c thalamus, the medial pronucleus was well preserved, whereas the rest of them, particularly the central and dorsal pronuclei, were morphologically very altered but mostly preserved specific marker expression (only Lhx2 and Neurog2 were abolished in some nuclei).
The medial pronucleus is preserved in the Shh-c thalamus Central pronucleus (anterior and ventral nuclear groups)

The mutant anterior thalamic nuclei could be recognized by their preserved Cdh6 expression and their relation to the external medullary lamina. The anterior thalamic nuclei lost, however, $L h \times 2$ and Neurog2 expression (Fig. 4C,D). The ventral group lost the expression of Neurog2 (Fig. 4I) and preserved only the most reduced expression of $\mathrm{Cdh} 6$ (Fig. 4J,O). The entire central pronucleus (anterior plus ventral groups) seemed reduced to a rostro- 


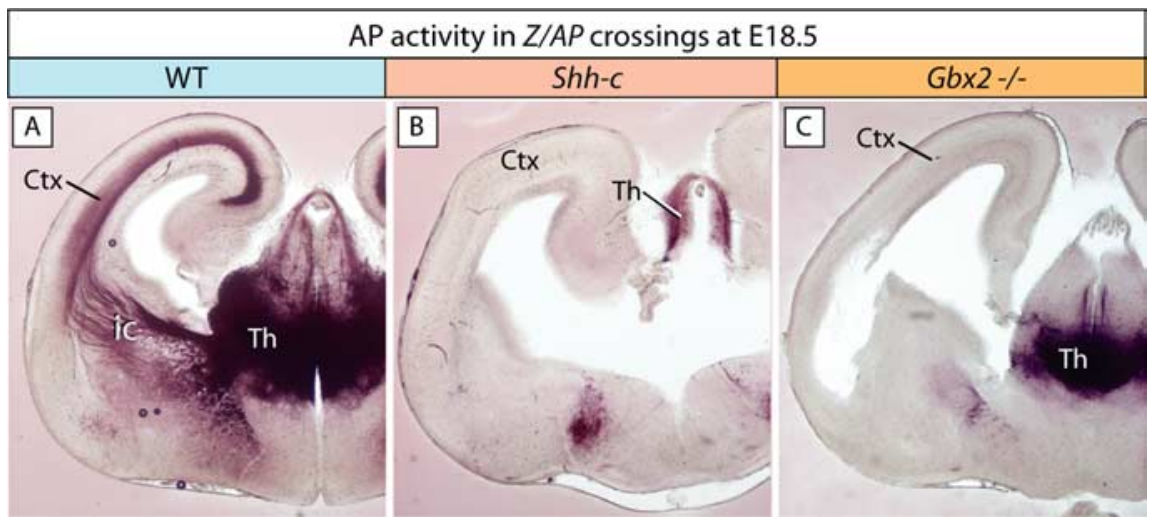

Figure 5. No thalamic axons reach the cortex in the Shh-c brain. Detection of alkaline phosphatase activity in transverse sections of wild-type $(\boldsymbol{A})$, Shh-c $(\boldsymbol{B})$, and $G b \times 2^{-/-}(\boldsymbol{C})$ brains at E18.5. The wild-type cortex $(\boldsymbol{A})$ shows abundant labeled thalamic axons in the cortex, whereas the $\operatorname{Shh}-c(B)$ and the $G b \times 2^{-/-}(\boldsymbol{C})$ cortices are completely unlabeled.

Table 4. Markers and nuclei in the $G b \times 2^{-/-}$thalamus

\begin{tabular}{|c|c|c|c|c|c|c|}
\hline Pronuclei & Nuclei & Calb2 & $G b \times 2^{*}$ & Lhx2 & Neurog2 & Cdh6 \\
\hline \multirow[t]{3}{*}{ Central } & ATN & ! & & & - & $?$ \\
\hline & VEN & & & $?$ & $?$ & $?$ \\
\hline & $\mathrm{VMb}$ & + & + & - & & + \\
\hline \multirow[t]{4}{*}{ Medial } & PV, PT, MV & - & $?$ & $?$ & & \\
\hline & MD & & $?$ & & & \\
\hline & $\mathrm{CM}$ & & $?$ & $?$ & & $?$ \\
\hline & $\mathrm{CL}$ & & $?$ & $?$ & & \\
\hline \multirow[t]{3}{*}{ Dorsal } & LD & - & & - & - & \\
\hline & $\mathrm{LP}$ & - & - & - & & + \\
\hline & $P_{0}$ & & & & & + \\
\hline Lateral geniculate & $\mathrm{LGd}$ & & & & + & + \\
\hline Medial geniculate & MG & + & + & + & & + \\
\hline
\end{tabular}

? indicates "normal" marker expression in a morphologically altered part of the thalamus identified by its position along the anteroposterior and dorsoventral axes and comparison with wild type. - indicates abnormal lack of expression. + indicates normal expression in a readily recognizable structure. ! indicates ectopic expression. * indicates ISH detection of the truncated, nonfunctional Gbx2 mRNA in the Gbx2 mutant.

caudal row of Cdh6-expressing cells (Fig. 4J,O, arrows). The tail of the central pronucleus (the ventromedial basal) was an exception, because it lost Calb2 and Cdh6 but still expressed Gbx2 and Lhx2 in the mutant (Fig. 4Q,R).

Medial pronucleus (medial and intralaminar nuclear groups)

This pronucleus was well preserved in morphology and marker expression, including Calb2 (Fig. 4A,F,K), Lhx2 (Fig. 4C, H, M), and $G b \times 2$ (Fig. $4 B, G, L$ ). Expression of $G b \times 2$ labeled the entire pronucleus and is an argument toward including the intralaminar nuclei in this medial pronucleus (not the central) (Rose, 1942).

Dorsal pronucleus (lateral and posterior nuclear groups)

The laterodorsal nucleus, expressing Calb2, was present in the mutant (Fig. $4 F$ ) but lacked expression of markers $L h \times 2$ and Neurog2 (Fig. 4H,I). The lateral posterior nucleus preserved Calb2, Gbx2, and Cdh6 expression (Fig. $4 K, L, O$ ) but lost $L h \times 2$ (Fig. $4 M$ ). The posterior nucleus appeared lost, to judge by $C d h 6$ expression (Fig. 4J).

Lateral geniculate pronucleus

We could not identify a lateral geniculate nucleus in the Shh-c thalamus.

\section{Medial geniculate pronucleus}

The medial geniculate pronucleus preserved expression of Calb2 and $G b \times 2$ (Fig. 4P,Q) but lost $L h \times 2$ and Cdh6 in the mutant (Fig. $4 R, T)$.
In summary, the medial pronucleus (in which we include the intralaminar group) was comparatively little affected by lack of neural Shh, whereas the other four pronuclei showed major alteration.

\section{No thalamocortical axons in the Shh-c mutant}

Extension of axons projecting to the cortex is an important differentiation trait of thalamic neurons (for review, see López-Bendito and Molnár, 2003). To explore this capability in the Shh-c mutant thalamus, we crossed our Shh-c line with the reporter mouse line Z/AP (Lobe et al., 1999), which results in labeling of the axons of Foxb1 lineage cells (see Materials and Methods). Because the entire thalamus belongs to the Foxb1 lineage (Fig. 1E) (Zhao et al., 2008), Foxb1-Cre Z/AP mice showed staining of thalamocortical axons as expected (Fig. $5 A$ ). The Shh-c mutant, however, showed a completely blank cortex (Fig. 5B). The second mutant used in this study, the Gbx2deficient mouse (see below), also lacked thalamocortical axons (Fig. 5C) as reported previously (Miyashita-Lin et al., 1999; Hevner et al., 2002).

\section{No regionalization defect in the $G b \times 2$ mutant}

Gbx2 is a transcription factor specifically expressed in the entire mouse thalamic primordium starting at E11.5 (Bulfone et al., 1993a,b; Hashimoto-Torii et al., 2003) and is essential for thalamic development (Miyashita-Lin et al., 1999; Hevner et al., 2002). Because thalamic expression of $G b \times 2$ is under the control of Shh (Hashimoto-Torii et al., 2003), we were surprised to find a small domain of Gbx2 expression in the Shh-c thalamus at E12.5 (Fig. $2 \mathrm{~J}$, arrow), as well as essentially normal thalamic expression at E18.5 (Fig. $4 B, G, L, Q$ ). We asked whether this late, default expression of $G b \times 2$ in the absence of neural Shh was perhaps "rescuing" some traits of the wild-type phenotype in the Shh-c mutant, making its phenotype milder. Therefore, we wanted to compare the $G b \times 2^{-/-}$thalamus with the Shh-c thalamus. We used a Gbx2 mutant in which most of exon 2, containing the homeobox-coding sequence, has been deleted (Wassarman et al., 1997) (see Materials and Methods). First, we detected regional marker genes at E12.5 to assess regionalization in this mutant. Probes against Ptch1, Gli1, Nkx2-2, Lhx1, Emx2, Pax6, Dlx2, $D b x 1$, and Irx 3 detected no changes in the regionalization of the caudal diencephalon, except for the smaller size of the thalamus (data not shown). We then proceeded to analyze thalamic differentiation in the Gbx2 mutant at E18.5.

\section{Abolition of the medial pronucleus in the Gbx2 mutant}

As was the case for the Shh-c mutant, the Gbx2-deficient thalamus was smaller than normal but showed correct dorsoventral and anteroposterior axes, as judged from the presence of a morphologically recognizable habenula (epithalamus) dorsally and the medial geniculate nucleus caudally (see below) (Fig. 6, Table 4). Comparison of Tables $2-4$ shows that, in this mutant, the medial pronucleus is specifically altered in morphology, although it maintains marker expression. The central and dorsal pronuclei were very affected (like in the Shh-c), but the lateral and medial geniculate pronuclei seemed relatively intact. 


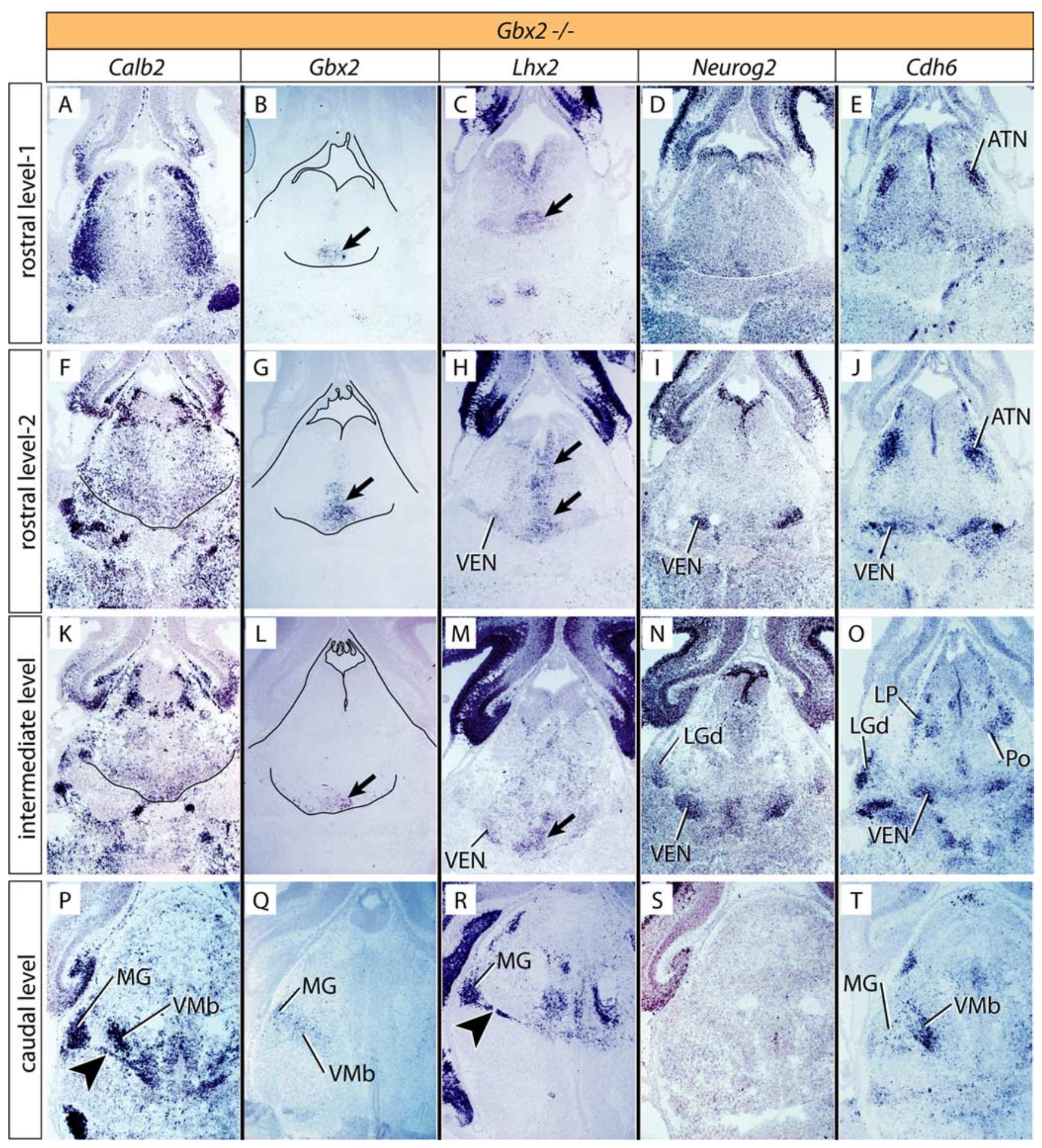

Figure 6. Marker expression in the E18.5 Gbx2 thalamus. $\boldsymbol{A}-\boldsymbol{T}$, In situ hybridization on E18.5 mouse brain sections for five marker genes as indicated on top of each column. Rows show sections at a given rostrocaudal level, as indicated on the left side, labeled for each of the five markers. Columns correspond to four rostrocaudal levels labeled with the same probe. The arrows in $\boldsymbol{B}, \boldsymbol{C}, \boldsymbol{G}, \boldsymbol{H}$, $\boldsymbol{L}$, and $\boldsymbol{M}$ indicate marker expression in morphologically abolished medial pronucleus. Some structures have been outlined for clarity. For details, see Results.

Central pronucleus (anterior and ventral nuclear groups)

The anterior group, although very much altered morphologically, showed ectopic Calb2 expression (Fig. 6A), lost Lhx2 (Fig. 6C,H) and Neurog2 (Fig. 6D,I), and preserved Cdh6 expression (Fig. $6 E, J$ ). The ventral group seemed reduced to a single rostrocaudal region preserving, however, all its markers (Lhx2, Neurog2, and Cdh6) (Fig. $6 \mathrm{H}-J, M-O$, VEN). The ventromedial basal preserved three of its four markers (Calb2,
Gbx2, and Cdh6) (Fig. 6P,Q,T) and lost $L h x 2$ (Fig. 6R). The smaller size of this nucleus in the $G b \times 2$ mutant brought to the fore a structure labeled by Calb2 and $L h \times 2$ and perhaps corresponding to the subparafascicular nucleus (Fig. $6 P, R$, arrowheads).

Medial pronucleus (medial and intralaminar nuclear groups) Truncated, nonfunctional Gbx2 mRNA can still be detected in the Gbx2 mutant (see Materials and Methods), allowing for rec- 

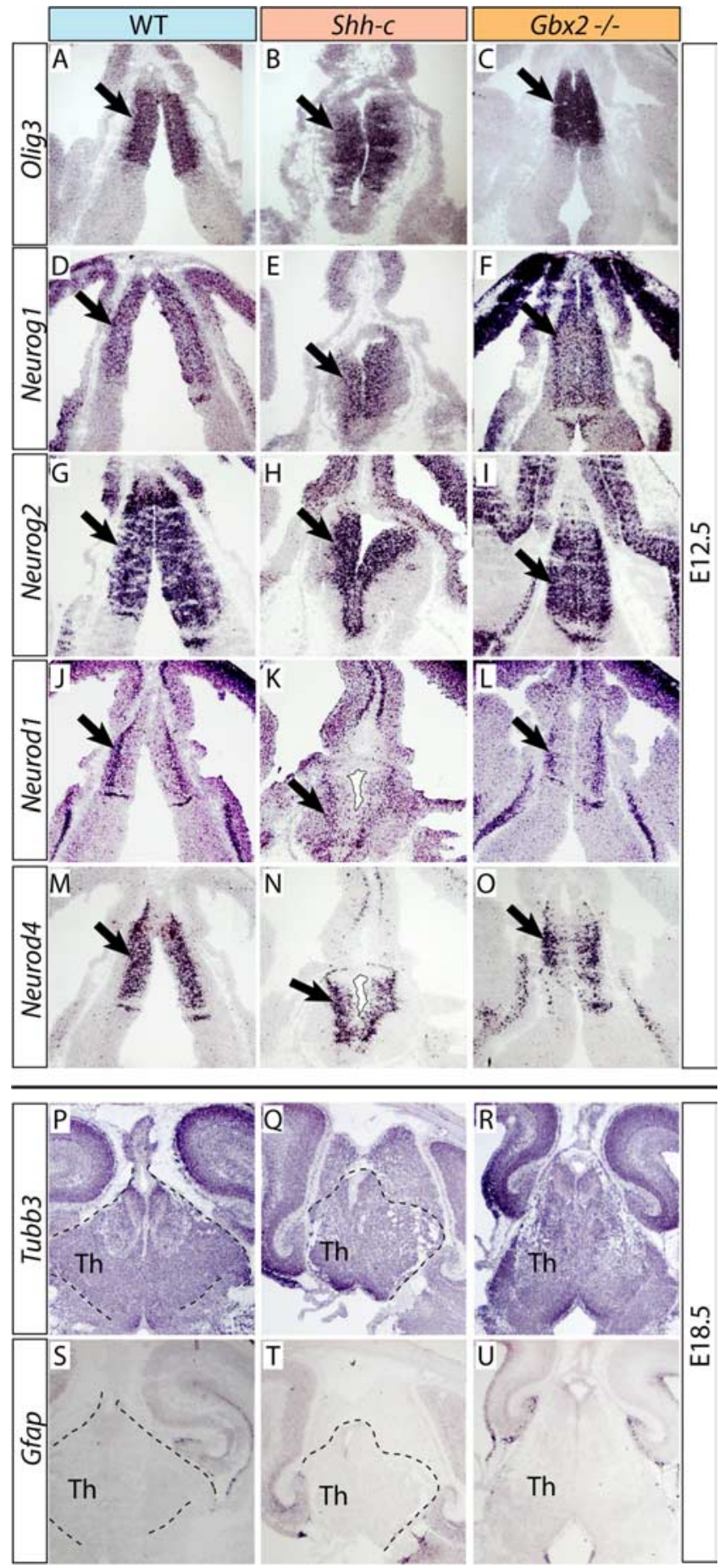

Figure 7. Differentiation markers in the thalamus. In situ detection of mRNA on transverse sections of E12.5 $(\boldsymbol{A}-\mathbf{0})$ or E18.5 $(\boldsymbol{P}-\boldsymbol{U})$ mouse brains for the genes and genotypes indicated. At E12.5, expression of Olig3 $(\boldsymbol{A}-\mathbf{C}), \operatorname{Neurog} 1(\boldsymbol{D}-\boldsymbol{F})$, Neurog2 (G-I), Neurod1 (J-L), and Neurod4 $(M-\mathbf{O})$ is maintained in the mutants. At E18.5, expression of pan-neuronal marker gene Tubb3 $(\boldsymbol{P}-\boldsymbol{R})$ and astroglial marker gene $G$ fap $(\boldsymbol{S}-\boldsymbol{U})$ does not show changes in the mutant brains. In $\boldsymbol{P}$, $Q, S$, and $I$, the thalamus has been outlined for clarity.

ognition of the medial pronucleus. This marker as well as $L h \times 2$ showed complete morphological abolition of the medial and intralaminar groups in the Gbx2 mutant (Fig. $6 B, C, G, H, L, M$, arrows).

Dorsal pronucleus (lateral and posterior nuclear groups)

The laterodorsal nucleus had disappeared, whereas the lateral posterior preserved Cdh6 expression (Fig. 6O) but lost Gbx2,
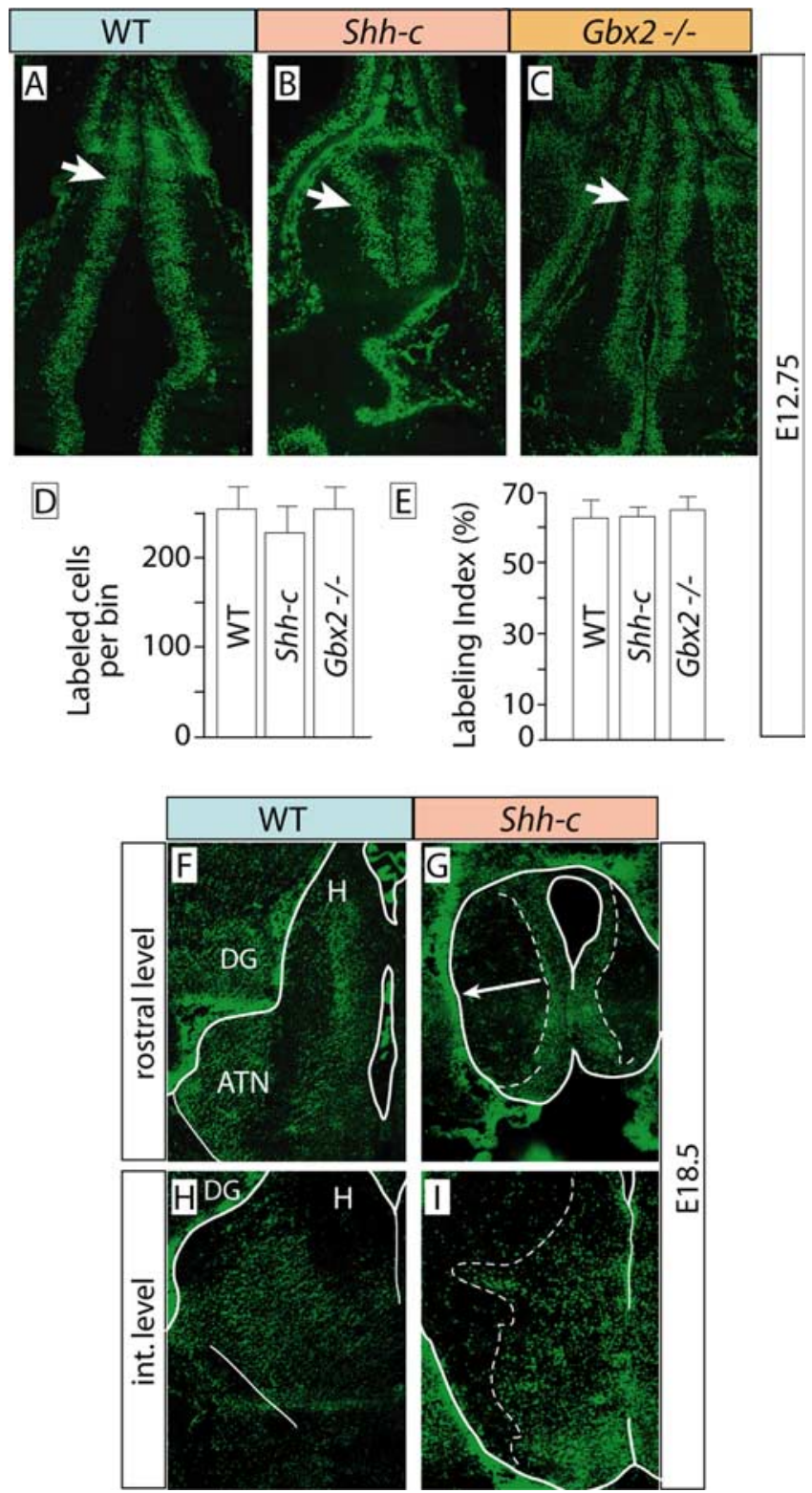

Figure 8. BrdU labeling in the mutant thalamus. $A-C$, BrdU-labeled sections of E12.75 thalamus of the three genotypes as indicated. White arrows indicate the labeled thalamic neuroepithelium. $\boldsymbol{D}, \boldsymbol{E}$, Results from counting absolute numbers of labeled cells $(\boldsymbol{D})$ and labeling index $(E)$ in the E12.75 thalamic neuroepithelium ( \pm SD) after 3 h. survival. No statistically significant differences were detected. $\boldsymbol{F}-\boldsymbol{I}$, BrdU-labeled cells (injection at E12.5, collection at E18.5) in the wild-type $(\boldsymbol{F}, \boldsymbol{H})$ and $\operatorname{Shh}-\boldsymbol{C}(\boldsymbol{G}, \boldsymbol{I})$ thalamus. The thalamus has been outlined in white. Rostrally $(\boldsymbol{F}, \boldsymbol{G})$, the wild type showed labeled cells at every mediolateral level, whereas in the Shh-c $(\boldsymbol{G})$, they were confined to a band surrounding the ventricle (dotted line), and the mantle layer (arrow) showed sparse labeling. More caudally $(\boldsymbol{H}, \boldsymbol{I})$, most labeled cells in the Shh-c $(\boldsymbol{I})$ did not progress beyond intermediate mediolateral levels (dotted line).

Calb2, and Lhx2 expression. The posterior nucleus preserved Cdh6 (Fig. 6O).

Lateral geniculate pronucleus

The lateral geniculate pronucleus preserved its two markers, Neurog2 and Cdh6 (Fig. 6N,O).

Medial geniculate pronucleus

The medial geniculate pronucleus preserved all its markers, Calb2, Gbx2, Lhx2, and Cdh6 (Fig. 6P-R,T). 
Basic helix-loop-helix gene expression in the mutant

thalamic neuroepithelium

The phenotypes observed could be the result of transdifferentiation or lack of differentiation attributable to incorrect activation of proneural genes, a family of basic helixloop-helix (bHLH) transcription factors governing fate acquisition (Guillemot, 2007a,b). Neurog1, Neurog2, and Olig3 are bHLH transcription factors with major roles in telencephalic fate acquisition (Fode et al., 2000) and also expressed in the thalamic neuroepithelium (González et al., 2002; Vue et al., 2007). Mining the expression pattern database GenePaint (www.genepaint.org) (Alvarez-Bolado and Eichele, 2006) for bHLH genes with developmental thalamic expression yielded two additional ones (Neurod1 and Neurod4). In situ hybridization labeling of the thalamic neuroepithelium at E12.5 did not show loss of expression of any of these five genes in the Shh-c and $G b \times 2$ mutants compared with the wild type (Fig. 7).

We then used in situ hybridization to label mRNA for the genes Tubb3 ( $\beta$ tubulin 3; a pan-neuronal marker) and Gfap (glial fibrillary acidic protein; an astroglial marker) to assess possible changes in cell type in the E18.5 mutant thalamus. Our results (Fig. $7 P-U$ ) showed no change in the neuron versus glia composition of the mutant thalamus.

\section{Cell proliferation in the mutant thalamic neuroepithelium}

Next we asked whether alterations in proliferation could be involved in the phenotypes observed. It is known that Shh deficiency results in decreased proliferation at approximately E9.0, i.e., during the period of expansion of neural precursors (Ishibashi and McMahon, 2002), as witnessed by the very small size of the early thalamic primordium in our Shh-c mutants. We wanted to investigate the proliferative capabilities of the $S h h-c$ neuroepithelium during the period of neuron production (i.e., after E11.0) (Altman and Bayer, 1988; Clancy et al., 2007). To this purpose, we labeled the thalamic neuroepithelium at E12.75 with BrdU (Fig. $8 A-C$ ). At this age, all rostrocaudal levels of the thalamic region should be actively proliferating (for details, see Material and Methods). We were not able to find statistically significant differences in absolute numbers of labeled cells or in labeling index between the three genotypes investigated, after either $1.5 \mathrm{~h}$ (data not shown) or $3 \mathrm{~h}$ survival (Fig. 8D,E).

\section{Distribution of BrdU labeling in the E18.5 Shh-c thalamus}

Migration alterations could contribute to the mutant thalamic phenotypes. To test this possibility, we wanted to examine the overall distribution in the thalamus of neurons born on a specific day. We labeled brains of the three genotypes with BrdU at E12.5 and collected them at E18.5, when most thalamic neurons have already been produced (Fig. $8 F-I$ ). In the wild-type thalamus (Fig. $8 F, H$ ) as well as the $G b \times 2$ mutant thalamus (data not shown), we could find labeled neurons at every mediolateral level of the thalamus, reaching the periphery of this region. However, in the Shh-c thalamus at the rostral level almost all labeled cells were confined to a band around the ventricle (Fig. $8 G$ ). This phenotype was less striking at more caudal levels, in which most labeled cells had reached intermediate mediolateral levels (Fig. $8 I$, dotted line), although only few were located in the periphery of the primordium.

Increase in neuronal apoptosis in the $G b \times 2$ mutant thalamus Increase in neuroepithelial (or "proliferative") apoptosis or in neuronal apoptosis could be at the root of the mutant phenotypes observed. Deficiency in Shh increases apoptosis in the diencephalic neuroepithelium during the phase of precursor expansion (Ishibashi and McMahon, 2002). To know whether Shh is necessary to prevent neuroepithelial cell death also during the phase of neuronal production, we labeled E12.5 thalamic sections by means of the TUNEL reaction. We found only very few apoptotic cells in the neuroepithelium of the three genotypes investigated and no evidence of an increase in apoptosis at this age (Fig. $9 A-F)$.

Next we asked whether neuronal cell death would be increased in our mutants. TUNEL sections of E18.5 thalamus at three ros- 

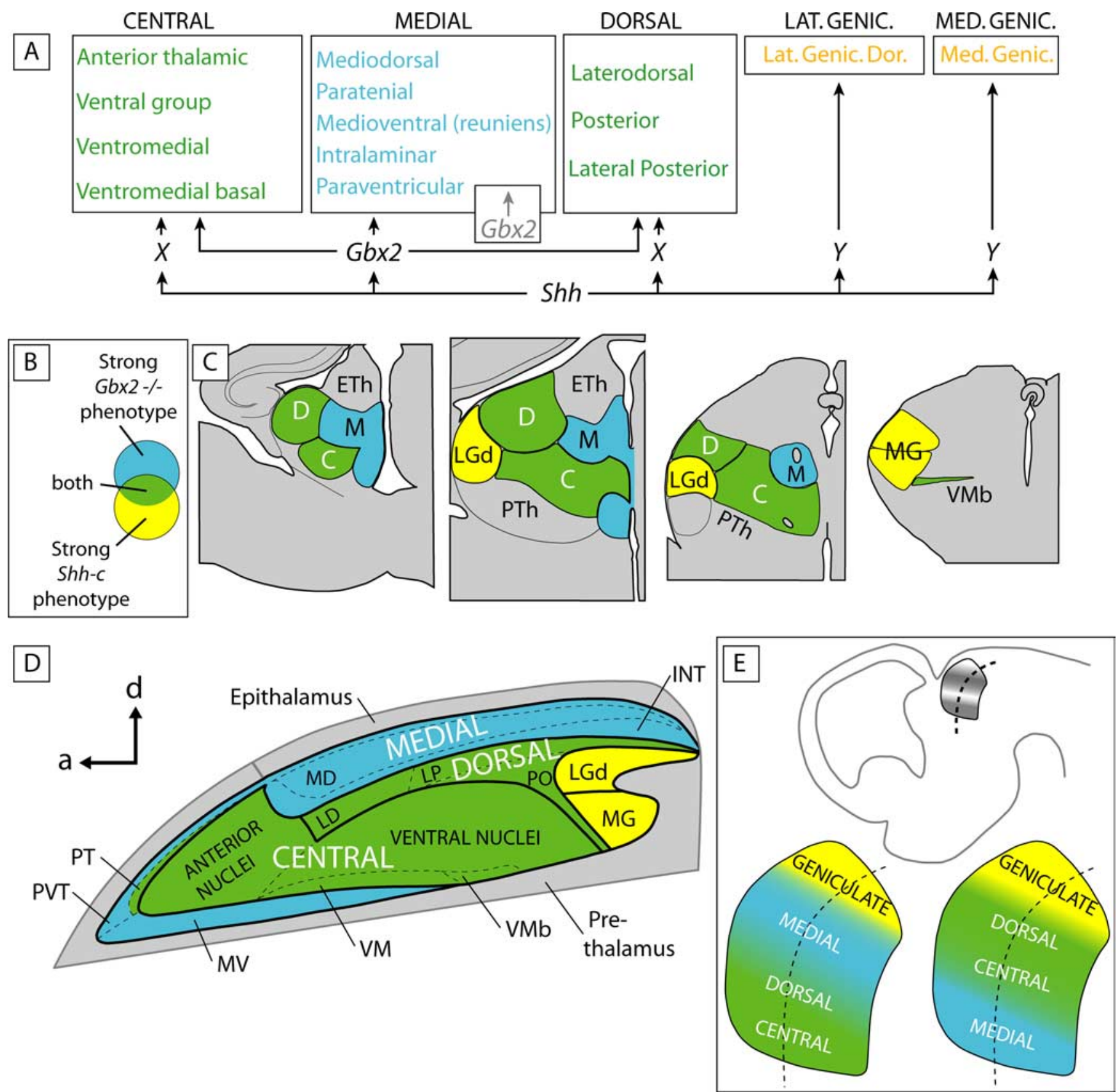

Figure 10. Summary of results. $A$, Involvement of $S h h, G b \times 2$ and unknown factors $(X, Y)$ in the differentiation of thalamic nuclear groups inferred from the mutant phenotypes. The Gbx2 label in a closed box symbolizes restricted default expression of Gbx2. We include the intralaminar nuclei in the medial pronucleus (see Results). Color code as in B. B, Color code for this figure. C, Diagram showing the thalamic pronuclei in four rostrocaudal levels labeled according to the severity of their phenotype in the Shh-c and Gbx2 mutants. $\boldsymbol{D}$, Thalamic nuclear groups mapped on a flat map (Swanson, 1992) and labeled according to dependence on Shh and/or Gbx2. Each of the three groups encompasses contiguous nuclei. E, Localization of the thalamic neuroepithelium (top) and possible arrangements of the three presumptive regions that will give rise to the different nuclear groups (bottom). Dotted line, Anteroposterior axis of thalamic primordium. C, Central; D, dorsal; M, medial; ETh, epithalamus.

trocaudal levels in the three genotypes (Fig. 9G-I) showed no change in neuronal cell death in Shh-c versus wild type (Fig. $9 J$ ). However, the Gbx2 mutant thalamus showed a very significant increase $(p<0.005)$ in neuronal cell death (Fig. 9J).

\section{Discussion}

Assessing thalamic differentiation with marker genes

Our identification of thalamic nuclear markers (Table 2) agrees with the literature (Arai et al., 1991, 1992, 1994; Frassoni et al., 1991; Winsky et al., 1992; Nakagawa and O'Leary, 2001; Jones and Rubenstein, 2004) except for minor discrepancies probably attributable to species (mouse vs rat) or age
[E18.5 vs postnatal day 0 (P0), P2, or adult) differences. We have not found Gbx2 expression in the anterior thalamus, but Jones and Rubenstein (2004) described it in the anterodorsal nucleus at $\mathrm{P} 0$. These authors do not mention lateral posterior nucleus expression of Cdh6, as we do. Lhx2 expression in the anterior, ventral, and lateral groups, as well as Neurog2 in the laterodorsal nucleus (Table 2), are not mentioned by Nakagawa and O'Leary (2001), working on P2. Finally, we do not find Calb2 in the mediodorsal nucleus, contrary to Arai et al. (1994), working on adult rat.

These discrepancies do not bear on the reliability of our con- 
clusions because, in every case, we have other markers plus clear ISH evidence obtained through a particularly sensitive dualamplification protocol.

\section{Neural Shh in the cascade of thalamic differentiation}

The development of a brain region proceeds by steps regulated by a hierarchical cascade of gene activation. Because the Shh-c mutant expresses thalamic marker $D b x 1$ (Fig. $2 G, H$ ), which is missing in the full Shh mutant (Ishibashi and McMahon, 2002), we can assume that the first steps of the thalamic cascade (regional specification) are not regulated by neural Shh. In any case, Shh is one among several factors in thalamic regionalization, because transcription factor gene Pax6, required for thalamic development (Warren and Price, 1997; Pratt et al., 2000, 2002), is expressed in the full Shh mutant (Ishibashi and McMahon, 2002). It is only after gastrulation (and general regional specification) that neural Shh signaling gets underway, activating $G b \times 2, N k \times 2-2$, and Sox14 and repressing Pax6 (Ishibashi and McMahon, 2002; Hashimoto-Torii et al., 2003; Kiecker and Lumsden, 2004) in a thalamus already specified regionally.

We hypothesized that neural Shh would promote the last steps of the thalamic specification cascade (partially through Gbx2 activation), leading to specific thalamic histogenesis and nucleogenesis. Our analysis of the mutant phenotypes confirms this hypothesis by showing that neural Shh has at least two roles: (1) promotion of specific neuronal aggregation, leading to the formation of recognizable thalamic nuclei; (2) promotion of axonal extension, leading [through a tightly regulated process (LópezBendito and Molnár, 2003; Price et al., 2006)] to appropriate thalamocortical connectivity.

\section{Neural Shh and neuronal fate acquisition in the thalamus}

However, earlier events such as incorrect neuronal fate acquisition could contribute to the mutant phenotypes reported here. The acquisition of general neuronal fate as well as some neuronal subtype traits are regulated by proneural genes, encoding bHLH transcription factors whose role in telencephalic development is well known (Guillemot, 2007a,b). Although there is evidence of a link between Shh and proneural and other bHLH genes (Blader et al., 1997; Lu et al., 2000; Ota and Ito, 2003; Andersson et al., 2006), the thalamic bHLH genes examined and the cell-type markers Tubb3 and Gfap were not changed in the mutant. This agrees with our hypothesis that neural Shh influences later stages of differentiation.

\section{Neurogenesis and proliferative cell death are not affected by neural Shh}

Shh promotes precursor proliferation in the thalamus, hypothalamus, and cortex (Dahmane et al., 2001; Ishibashi and McMahon, 2002; Manning et al., 2006). The very small size of the early Shh-c thalamic primordium confirms this role. A role for Shh in neuron generation has not yet been documented (except for an indirect function in cortical interneuron generation) (Gulacsi and Lillien, 2003). In agreement, we show that deficiency in neuroepithelial Shh does not impair proliferation during the phase of neurogenesis.

Normally occurring cell death is a key developmental process that can affect the proliferative neuroepithelium (so-called proliferative cell death) (Thomaidou et al., 1997) as well as postmitotic neurons (see below). Although Shh is a neuroepithelial survival factor during precursor proliferation (Ishibashi and McMahon, 2002), we show that later deficiency in Shh does not increase neuroepithelial cell death. This suggests that Shh (of any origin) acts specifically on the neuronal progenitors during the phase of expansion.

\section{Migration in the Shh-c mutant thalamus}

In the cortex, it is possible to follow neuronal migration to different layers by using precisely timed BrdU injections (Edgar and Price, 2001). Thalamic neuronal migration does not result in layer formation, but the principle of labeling a certain population with BrdU and recording its position at a later stage holds also for the thalamus. In this way, we have detected alteration in neuronal distribution in the E18.5 Shh-c thalamus, compatible with slow or failed migration. Inability of neurons to reach their settling places would alter specific neuronal aggregation (i.e., nucleogenesis and histogenesis) and would help explain the Shh-c mutant phenotype. Hedgehog signaling can influence the migration of glia and neurons in the developing fruit fly (Rangarajan et al., 2001). Shh has an indirect influence on the migration of newly born neurons in the adult mouse (Balordi and Fishell, 2007). Even if a comprehensive analysis of the role of Shh in migration is not intended here, our results indicate a possible function of neural Shh in the radial migration of newly born thalamic neurons.

\section{Gbx2 is necessary for neuronal survival}

Normally occurring developmental neuronal death (Oppenheim, 1991) appears in the rodent thalamus during the first postnatal week (Ashwell and Waite, 1991; Spreafico et al., 1995; Alcántara et al., 1997; Lotto et al., 2001; Luczyńska et al., 2003). Accordingly, we found few apoptotic figures in the wild-type and the Shh-c thalamus at E18.5. Thalamic neuronal survival during development depends on endogenous and target-derived factors (Lotto et al., 1997, 2001), a mechanism not altered by neural Shh deficiency.

We show, however, very increased neuronal cell death in the $G b \times 2$ mutant thalamus, indicating that $G b \times 2$ has a hitherto unknown role in the survival of specific neuronal populations. Obviously, a major cause of the $G b \times 2$ thalamic phenotype is massive cell death.

\section{$G b \times 2$ is necessary and sufficient to specify the medial pronucleus}

$G b \times 2$ is initially expressed at E11.5 in the entire thalamic primordium downstream Shh (Hashimoto-Torii et al., 2003). However, we show delayed and restricted expression of $G b \times 2$ independent of Shh. Because in the Shh-c mutant the medial pronucleus preserved general shape and gene expression whereas in the Gbx2 mutant it showed complete and specific morphological abolition, it follows that $G b \times 2$ is necessary and sufficient to specify cell fate and position of the medial and intralaminar groups (in a thalamic primordium already specified as a region).

The lateral and medial geniculate pronuclei, however, depend on $S h h$, not $G b x 2$, for differentiation. Finally, the central and dorsal pronuclei depend on both neural Shh and Gbx2. The resultant $S h h-G b \times 2$-thalamic differentiation cascade misses (at least) two components (Fig. $10 \mathrm{~A}, X$ and $Y$ ) that would be responsible for the specific effects of Shh. Component $X$ could simply be the early expression (E11.5) of $G b \times 2$ in the entire primordium.

\section{Prepatterning the thalamic neuroepithelium}

The existence of an early, Shh-independent pattern ("prepattern") in the spinal cord has been proposed to explain why the phenotype of Gli compound mutants is less severe than expected 
(Ruiz i Altaba et al., 2003). Thalamic prepatterning depends on Wnt activity upstream Irx3 (Braun et al., 2003), which makes the thalamic neuroepithelium competent to respond to Shh (Kiecker and Lumsden, 2004). We show an additional thalamic prepatterning phenomenon resulting in a late phase of neural Shhindependent $G b \times 2$ expression. The pronuclei, labeled according to their differential Shh or Gbx2 dependence (Fig. 10A,B), have a complex tridimensional relation to each other (Fig. 10C). However, when they are depicted on a "flat map" (Fig. 10D) (after Swanson, 1992), it becomes evident that each of the three groups encompasses adjacent nuclei that could originate in contiguous neuroepithelial areas. The thalamic neuroepithelium would then be patterned into at least three areas whose spatial arrangement is not yet clear (Fig. $10 \mathrm{E}$, bottom).

Finally, our results bear on a current question about the basic developmental mechanisms patterning the thalamus. Does neural Shh specify thalamic neurons through a concentration gradient? This mechanism is used by the notochord to specify the ventral spinal cord (Jessell, 2000), and it would be an elegant way to specify the intricate thalamic structure. However, the existence of a (neural) Shh-independent area in the thalamic neuroepithelium implies that a concentration gradient would have to work around a nonresponsive patch of tissue (Fig. $10 \mathrm{E}$ ). This suggests that any concentration gradient mechanism in the thalamus would have to adopt a more complex form than in the ventral spinal cord.

\section{References}

Alcántara S, Frisén J, del Río JA, Soriano E, Barbacid M, Silos-Santiago I (1997) TrkB signaling is required for postnatal survival of CNS neurons and protects hippocampal and motor neurons from axotomy-induced cell death. J Neurosci 17:3623-3633.

Altman J, Bayer SA (1988) Development of the rat thalamus: I. Mosaic organization of the thalamic neuroepithelium. J Comp Neurol 275:346-377.

Alvarez-Bolado G, Zhou X, Voss AK, Thomas T, Gruss P (2000) Winged helix transcription factor Foxb1 is essential for access of mammillothalamic axons to the thalamus. Development 127:1029-1038.

Alvarez-Bolado G, Eichele G (2006) Analysing the developing brain transcriptome with the GenePaint platform. J Physiol 575:347-352.

Andersson E, Tryggvason U, Deng Q, Friling S, Alekseenko Z, Robert B, Perlmann T, Ericson J (2006) Identification of intrinsic determinants of midbrain dopamine neurons. Cell 124:393-405.

Arai R, Winsky L, Arai M, Jacobowitz DM (1991) Immunohistochemical localization of calretinin in the rat hindbrain. J Comp Neurol 310:21-44.

Arai M, Arai R, Kani K, Jacobowitz DM (1992) Immunohistochemical localization of calretinin in the rat lateral geniculate nucleus and its retinogeniculate projection. Brain Res 596:215-222.

Arai R, Jacobowitz DM, Deura S (1994) Distribution of calretinin, calbindin-D28k, and parvalbumin in the rat thalamus. Brain Res Bull 33:595-614.

Ashwell KW, Waite PM (1991) Cell death in the developing trigeminal nuclear complex of the rat. Brain Res Dev Brain Res 63:291-295.

Bachy I, Vernier P, Retaux S (2001) The LIM-homeodomain gene family in the developing Xenopus brain: conservation and divergences with the mouse related to the evolution of the forebrain. J Neurosci 21:7620-7629.

Balordi F, Fishell G (2007) Hedgehog signaling in the subventricular zone is required for both the maintenance of stem cells and the migration of newborn neurons. J Neurosci 27:5936-5947.

Blader P, Fischer N, Gradwohl G, Guillemot F, Strähle U (1997) The activity of neurogenin 1 is controlled by local cues in the zebrafish embryo. Development 124:4557-4569.

Braun MM, Etheridge A, Bernard A, Robertson CP, Roelink H (2003) Wnt signaling is required at distinct stages of development for the induction of the posterior forebrain. Development 130:5579-5587.

Bulfone A, Kim HJ, Puelles L, Porteus MH, Grippo JF, Rubenstein JL (1993a) The mouse Dlx-2 (Tes-1) gene is expressed in spatially restricted domains of the forebrain, face and limbs in midgestation mouse embryos. Mech Dev 40:129-140.
Bulfone A, Puelles L, Porteus MH, Frohman MA, Martin GR, Rubenstein JL (1993b) Spatially restricted expression of Dlx-1, Dlx-2 (Tes-1), Gbx-2, and Wnt-3 in the embryonic day 12.5 mouse forebrain defines potential transverse and longitudinal segmental boundaries. J Neurosci 13:3155-3172.

Clancy B, Darlington RB, Finlay BL (2001) Translating developmental time across mammalian species. Neuroscience 105:7-17.

Clancy B, Kersh B, Hyde J, Darlington RB, Anand KJ, Finlay BL (2007) Web-based method for translating neurodevelopment from laboratory species to humans. Neuroinformatics 5:79-94.

Dahmane N, Sánchez P, Gitton Y, Palma V, Sun T, Beyna M, Weiner H, Ruiz i Altaba A (2001) The Sonic Hedgehog-Gli pathway regulates dorsal brain growth and tumorigenesis. Development 128:5201-5212.

Dassule HR, Lewis P, Bei M, Maas R, McMahon AP (2000) Sonic hedgehog regulates growth and morphogenesis of the tooth. Development 127:4775-4785.

Dessaud E, McMahon AP, Briscoe J (2008) Pattern formation in the vertebrate neural tube: a sonic hedgehog morphogen-regulated transcriptional network. Development 135:2489-2503.

Edgar JM, Price DJ (2001) Radial migration in the cerebral cortex is enhanced by signals from thalamus. Eur J Neurosci 13:1745-1754.

Fan CM, Porter JA, Chiang C, Chang DT, Beachy PA, Tessier-Lavigne M (1995) Long-range sclerotome induction by sonic hedgehog: direct role of the amino-terminal cleavage product and modulation by the cyclic AMP signaling pathway. Cell 81:457-465.

Fields-Berry SC, Halliday AL, Cepko CL (1992) A recombinant retrovirus encoding alkaline phosphatase confirms clonal boundary assignment in lineage analysis of murine retina. Proc Natl Acad Sci U S A 89:693-697.

Fode C, Ma Q, Casarosa S, Ang SL, Anderson DJ, Guillemot F (2000) A role for neural determination genes in specifying the dorsoventral identity of telencephalic neurons. Genes Dev 14:67-80.

Frassoni C, Bentivoglio M, Spreafico R, Sánchez MP, Puelles L, Fairen A (1991) Postnatal development of calbindin and parvalbumin immunoreactivity in the thalamus of the rat. Brain Res Dev Brain Res 58:243-249.

Frassoni C, Arcelli P, Selvaggio M, Spreafico R (1998) Calretinin immunoreactivity in the developing thalamus of the rat: a marker of early generated thalamic cells. Neuroscience 83:1203-1214.

González G, Puelles L, Medina L (2002) Organization of the mouse dorsal thalamus based on topology, calretinin immunostaining, and gene expression. Brain Res Bull 57:439-442.

Guillemot F (2007a) Cell fate specification in the mammalian telencephalon. Prog Neurobiol 83:37-52.

Guillemot F (2007b) Spatial and temporal specification of neural fates by transcription factor codes. Development 134:3771-3780.

Gulacsi A, Lillien L (2003) Sonic hedgehog and bone morphogenetic protein regulate interneuron development from dorsal telencephalic progenitors in vitro. J Neurosci 23:9862-9872.

Gustincich S, Feigenspan A, Wu DK, Koopman LJ, Raviola E (1997) Control of dopamine release in the retina: a transgenic approach to neural networks. Neuron 18:723-736.

Hashimoto-Torii K, Motoyama J, Hui CC, Kuroiwa A, Nakafuku M, Shimamura K (2003) Differential activities of Sonic hedgehog mediated by Gli transcription factors define distinct neuronal subtypes in the dorsal thalamus. Mech Dev 120:1097-1111.

Hevner RF, Miyashita-Lin E, Rubenstein JL (2002) Cortical and thalamic axon pathfinding defects in Tbr1, Gbx2, and Pax6 mutant mice: evidence that cortical and thalamic axons interact and guide each other. J Comp Neurol 447:8-17.

Hynes M, Porter JA, Chiang C, Chang D, Tessier-Lavigne M, Beachy PA, Rosenthal A (1995) Induction of midbrain dopaminergic neurons by Sonic hedgehog. Neuron 15:35-44.

Ishibashi M, McMahon AP (2002) A sonic hedgehog-dependent signaling relay regulates growth of diencephalic and mesencephalic primordia in the early mouse embryo. Development 129:4807-4819.

Jessell TM (2000) Neuronal specification in the spinal cord: inductive signals and transcriptional codes. Nat Rev Genet 1:20-29.

Jones EG (2007a) Principles of thalamic organization. In: The thalamus, pp 87-170. Cambridge: Cambridge UP.

Jones EG (2007b) Part III. Development. In: The thalamus, pp 481-609. Cambridge: Cambridge UP.

Jones EG, Rubenstein JL (2004) Expression of regulatory genes during dif- 
ferentiation of thalamic nuclei in mouse and monkey. J Comp Neurol 477:55-80.

Kiecker C, Lumsden A (2004) Hedgehog signaling from the ZLI regulates diencephalic regional identity. Nat Neurosci 7:1242-1249.

Kitamura K, Miura H, Yanazawa M, Miyashita T, Kato K (1997) Expression patterns of Brx1 (Rieg gene), Sonic hedgehog, Nkx2.2, Dlx1 and Arx during zona limitans intrathalamica and embryonic ventral lateral geniculate nuclear formation. Mech Dev 67:83-96.

Kloetzli JM, Fontaine-Glover IA, Brown ER, Kuo M, Labosky PA (2001) The winged helix gene, Foxb1, controls development of mammary glands and regions of the CNS that regulate the milk-ejection reflex. Genesis 29:60-71.

Leighton PA, Mitchell KJ, Goodrich LV, Lu X, Pinson K, Scherz P, Skarnes WC, Tessier-Lavigne M (2001) Defining brain wiring patterns and mechanisms through gene trapping in mice. Nature 410:174-179.

Lewis PM, Dunn MP, McMahon JA, Logan M, Martin JF, St-Jacques B, McMahon AP (2001) Cholesterol modification of sonic hedgehog is required for long-range signaling activity and effective modulation of signaling by Ptc1. Cell 105:599-612.

Lobe CG, Koop KE, Kreppner W, Lomeli H, Gertsenstein M, Nagy A (1999) $\mathrm{Z} / \mathrm{AP}$, a double reporter for cre-mediated recombination. Dev Biol 208:281-292.

López-Bendito G, Molnár Z (2003) Thalamocortical development: how are we going to get there? Nat Rev Neurosci 4:276-289.

López-Martínez A, Chang DT, Chiang C, Porter JA, Ros MA, Simandl BK, Beachy PA, Fallon JF (1995) Limb-patterning activity and restricted posterior localization of the amino-terminal product of Sonic hedgehog cleavage. Curr Biol 5:791-796.

Lotto RB, Clausen JA, Price DJ (1997) A role for neurotrophins in the survival of murine embryonic thalamic neurons. Eur J Neurosci 9:1940-1949.

Lotto RB, Asavaritikrai P, Vali L, Price DJ (2001) Target-derived neurotrophic factors regulate the death of developing forebrain neurons after a change in their trophic requirements. J Neurosci 21:3904-3910.

Lu QR, Yuk D, Alberta JA, Zhu Z, Pawlitzky I, Chan J, McMahon AP, Stiles CD, Rowitch DH (2000) Sonic hedgehog-regulated oligodendrocyte lineage genes encoding bHLH proteins in the mammalian central nervous system. Neuron 25:317-329.

Luczyñska A, Dziewiatkowski J, Jagalska-Majewska H, Kowiañski P, Wójcik S, Labuda C, Moryo J (2003) Qualitative and quantitative analysis of the postnatal development of the ventroposterolateral nucleus of the thalamus in rat and rabbit. Folia Morphol (Warsz) 62:75-87.

Manning L, Ohyama K, Saeger B, Hatano O, Wilson SA, Logan M, Placzek M (2006) Regional morphogenesis in the hypothalamus: a BMP-Tbx2 pathway coordinates fate and proliferation through Shh downregulation. Dev Cell 11:873-885.

Martí E, Bumcrot DA, Takada R, McMahon AP (1995) Requirement of 19K form of Sonic hedgehog for induction of distinct ventral cell types in CNS explants. Nature 375:322-325.

Miyashita-Lin EM, Hevner R, Wassarman KM, Martinez S, Rubenstein JL (1999) Early neocortical regionalization in the absence of thalamic innervation. Science 285:906-909.

Nakagawa Y, O'Leary DD (2001) Combinatorial expression patterns of LIM-homeodomain and other regulatory genes parcellate developing thalamus. J Neurosci 21:2711-2725.

Oppenheim RW (1991) Cell death during development of the nervous system. Annu Rev Neurosci 14:453-501.

Ota M, Ito K (2003) Induction of neurogenin-1 expression by sonic hedgehog: Its role in development of trigeminal sensory neurons. Dev Dyn 227:544-551.

Pratt T, Vitalis T, Warren N, Edgar JM, Mason JO, Price DJ (2000) A role for Pax6 in the normal development of dorsal thalamus and its cortical connections. Development 127:5167-5178.

Pratt T, Quinn JC, Simpson TI, West JD, Mason JO, Price DJ (2002) Disruption of early events in thalamocortical tract formation in mice lacking the transcription factors Pax6 or Foxg1. J Neurosci 22:8523-8531.

Price DJ, Kennedy H, Dehay C, Zhou L, Mercier M, Jossin Y, Goffinet AM, Tissir F, Blakey D, Molnár Z (2006) The development of cortical connections. Eur J Neurosci 23:910-920.

Rangarajan R, Courvoisier H, Gaul U (2001) Dpp and Hedgehog mediate neuron-glia interactions in Drosophila eye development by promoting the proliferation and motility of subretinal glia. Mech Dev 108:93-103.

Roelink H, Porter JA, Chiang C, Tanabe Y, Chang DT, Beachy PA, Jessell TM
(1995) Floor plate and motor neuron induction by different concentrations of the amino-terminal cleavage product of sonic hedgehog autoproteolysis. Cell 81:445-455.

Rose JE (1942) The ontogenetic development of the rabbit's diencephalon. J Comp Neurol 77:61-129.

Ruiz i Altaba A, Nguyên V, Palma V (2003) The emergent design of the neural tube: prepattern, $\mathrm{SHH}$ morphogen and GLI code. Curr Opin Genet Dev 13:513-521.

Scholpp S, Wolf O, Brand M, Lumsden A (2006) Hedgehog signalling from the zona limitans intrathalamica orchestrates patterning of the zebrafish diencephalon. Development 133:855-864.

Shimamura K, Hartigan DJ, Martinez S, Puelles L, Rubenstein JL (1995) Longitudinal organization of the anterior neural plate and neural tube. Development 121:3923-3933.

Shoji H, Ito T, Wakamatsu Y, Hayasaka N, Ohsaki K, Oyanagi M, Kominami R, Kondoh H, Takahashi N (1996) Regionalized expression of the Dbx family homeobox genes in the embryonic CNS of the mouse. Mech Dev 56:25-39.

Soriano P (1999) Generalized lacZ expression with the ROSA26 Cre reporter strain. Nat Genet 21:70-71.

Spreafico R, Frassoni C, Arcelli P, Selvaggio M, De Biasi S (1995) In situ labeling of apoptotic cell death in the cerebral cortex and thalamus of rats during development. J Comp Neurol 363:281-295.

Swanson LW (1992) Brain maps: the structure of the adult rat brain. Amsterdam: Elsevier.

Takahashi T, Nowakowski RS, Caviness VS Jr (1993) Cell cycle parameters and patterns of nuclear movement in the neocortical proliferative zone of the fetal mouse. J Neurosci 13:820-833.

Thomaidou D, Mione MC, Cavanagh JF, Parnavelas JG (1997) Apoptosis and its relation to the cell cycle in the developing cerebral cortex. J Neurosci 17:1075-1085.

Vieira C, Martinez S (2006) Sonic hedgehog from the basal plate and the zona limitans intrathalamica exhibits differential activity on diencephalic molecular regionalization and nuclear structure. Neuroscience 143:129-140.

Vieira C, Garda AL, Shimamura K, Martinez S (2005) Thalamic development induced by Shh in the chick embryo. Dev Biol 284:351-363.

Visel A, Alvarez-Bolado G, Thaller C, Eichele G (2006) Comprehensive analysis of the expression patterns of the adenylate cyclase gene family in the developing and adult mouse brain. J Comp Neurol 496:684-697.

Vue TY, Aaker J, Taniguchi A, Kazemzadeh C, Skidmore JM, Martin DM, Martin JF, Treier M, Nakagawa Y (2007) Characterization of progenitor domains in the developing mouse thalamus. J Comp Neurol 505:73-91.

Warren N, Price DJ (1997) Roles of Pax-6 in murine diencephalic development. Development 124:1573-1582.

Warren N, Caric D, Pratt T, Clausen JA, Asavaritikrai P, Mason JO, Hill RE, Price DJ (1999) The transcription factor, Pax6, is required for cell proliferation and differentiation in the developing cerebral cortex. Cereb Cortex 9:627-635.

Wassarman KM, Lewandoski M, Campbell K, Joyner AL, Rubenstein JL, Martinez S, Martin GR (1997) Specification of the anterior hindbrain and establishment of a normal mid/hindbrain organizer is dependent on Gbx2 gene function. Development 124:2923-2934.

Wilkinson DG (1992) In situ hybridization: a practical approach. Oxford: IRL.

Winsky L, Montpied P, Arai R, Martin BM, Jacobowitz DM (1992) Calretinin distribution in the thalamus of the rat: immunohistochemical and in situ hybridization histochemical analyses. Neuroscience 50:181-196.

Yaylaoglu MB, Titmus A, Visel A, Alvarez-Bolado G, Thaller C, Eichele G (2005) Comprehensive expression atlas of fibroblast growth factors and their receptors generated by a novel robotic in situ hybridization platform. Dev Dyn 234:371-386.

Zeltser LM (2005) Shh-dependent formation of the ZLI is opposed by signals from the dorsal diencephalon. Development 132:2023-2033.

Zhao T, Zhou X, Szabó N, Leitges M, Alvarez-Bolado G (2007) Foxb1driven Cre expression in somites and the neuroepithelium of diencephalon, brainstem, and spinal cord. Genesis 45:781-787.

Zhao T, Szabó N, Ma J, Luo L, Zhou X, Alvarez-Bolado G (2008) Genetic mapping of Foxb1-cell lineage shows migration from caudal diencephalon to telencephalon and lateral hypothalamus. Eur J Neurosci 28:19411955. 